\title{
Response surface optimization of D(-)-lactic acid production by Lactobacillus SMI8 using corn steep liquor and yeast autolysate as an alternative nitrogen source
}

\author{
Cristian J. Bolner de Lima*, Luciana Fontes Coelho, Kate Cristina Blanco and Jonas Contiero \\ Department of Biochemistry and Microbiology, Institute of Biological Sciences, São Paulo State University, UNESP/Rio \\ Claro, Av. 24-A, 1515 Bela Vista, ZIP CODE 13506-900, Rio Claro, SP, Brazil.
}

Accepted 9 July, 2009

\begin{abstract}
The production of D(-) lactic acid from Lactobacillus LMI8 sp. was studied, using 2 low-cost nitrogen sources: corn steep liquor (CSL) and yeast autolysate (YA). A central composite design was used to determine maximal lactic acid production. The surface response method was used to evaluate the results of the experiments. The assays were performed in $250 \mathrm{~mL}$ Erlenmeyer flasks containing $100 \mathrm{~mL}$ of production medium maintained under refrigerated incubation at $200 \mathrm{rpm}$ and a temperature of $37 \pm$ $1{ }^{\circ} \mathrm{C}$ for $48 \mathrm{~h}$ of fermentation. Lactic acid production was significantly affected by the isolated CSL as well as the interaction between CSL and YA. Maximal production of $D(+)$ lactic acid was $41.42 \mathrm{~g} / \mathrm{L}-\mathrm{a}$ value located at the central point, which corresponded to $15 \mathrm{~g} / \mathrm{L}$ of CSL and $5 \mathrm{~g} / \mathrm{L}$ of YA.
\end{abstract}

Key words: D(-)-Lactic acid, Lactobacillus, corn steep liquor, yeast autolysate, response surface methodology, medium optimization.

\section{INTRODUCTION}

Lactic acid is the common name given to 2-hydroxypropanoic acid (Datta et al., 1995), which is a versatile product that has found applications in diverse fields as an acidulant in the food and pharmaceutical industries (Schepers et al., 2002). With the development and commercialization of biopolymers, lactic acid use has increased considerably and 20 to $30 \%$ of the production was estimated to be in these new applications (Datta and Henry, 2006).

Lactic acid can be obtained either through chemical synthesis or fermentative processes (Chotani et al., 2000). The chemical pathway always leads to the formation of a racemic mixture, in which concentrations of the $\mathrm{D}(-)$ and $\mathrm{L}(+)$ forms are equal. In fermentative processes, only one of these forms is obtained $[\mathrm{D}(+)$ or $L(-)]$, depending on the bacterium chosen, or a mixture of the isomers is obtained in varied compositions (Hofvendahl and Hahn-Hagerdal, 2000).

${ }^{\star}$ Corresponding author. E-mail: cristian@rc.unesp.br. Tel.: +55 19 35264180. Fax: +55 1935264176.
It has recently been discovered that the mixture of the polymers $D(-)$ and $L(+)$ furnishes a recemic crystal known as complex-ester. This type of complex is characterized by a greater resistance to high temperatures, approxi-mately $50^{\circ} \mathrm{C}$ higher than polymerization in the L(+) form (Roy et al., 2002; Ikada et al., 1987; Tsuji et al., 1991; Takaaki et al., 2006). This has generated an increased important of the production of the $D(-)$ isomer .

Lactic acid bacteria make up a group of diverse microorganisms that are widely distributed in nature and associated to plants (kale, corn, barley), meat, milk products, porridge and silage. These lactobacilli are very demanding microorganisms that require fermentable carbohydrates, amino acids, B complex vitamins, nucleic acids and minerals for growth as well as nutrients that are specific to each strain (Gomes and Malcata, 1999).

A number of byproducts and raw materials from the food and/or agriculture industries have been employed for microorganism growth due to their considerable availability and low cost. Examples include cheese whey, corn steep liquor, corn syrup, distillery yeast and molasses (Moraes et al., 1991). In Brazil, lactic acid production 
from sugarcane and corn residuals has considerable economic appeal due to the abundance and low cost of these byproducts.

Molasses, which a by-product of the sugar manufacturing process, is used as an animal feed as well as for ethanol and yeast production (Focus, 1975). It can be also used for lactic acid production (El-Sherbiny et al., 1986; Tiwari et al., 1979). The most abundant sugar is sucrose, the high concentration of which raises the viscosity of the liquid (Focus, 1975). Moreover, molasses and corn steep liquor are prominent culture media in fermentative processes due to the high content of sugars and nitrogen, respectively (Beaulieu et al., 1995).

The aim of the present study was to investigate the production of lactic acid by Lactobacillus sp. LMI8 at a lower cost, employing a central composite design (CCD) and response surface method, using sugarcane molasses enriched with corn steep liquor and yeast autolysate as the culture medium.

\section{MATERIALS AND METHODS}

\section{Microorganisms}

The Lactobacillus sp. LMI8 used in the present study was isolated from a decantation tank of residuals from the flour industry (Plaza Starch Mill-Santa Maria-SP, Brazil). The culture was stored in Man, Rogosa and Sharpe (MRS) medium with $20 \%$ (v/v) glycerol at $80^{\circ} \mathrm{C}$.

\section{Isolation of LMI8 culture}

The successive dilution method was employed and plating was performed using the "pour plate" method. Bacterial strain selection was based on the greatest production of the $D(-)$ lactic acid isomer from the culture medium used in the fermentation process.

\section{Sugarcane molasses}

Sugarcane molasses was obtained from the santa lucia sugar processing plant located in the region of Araras-SP, Brazil. The molasses was diluted and hydrolyzed at a ratio of $1 \mathrm{~mL}$ of $\mathrm{H}_{2} \mathrm{SO}_{4}$ $(20 \%)$ in $100 \mathrm{~mL}$ of molasses solution and heated for $20 \mathrm{~min}$. After hydrolysis, the $\mathrm{pH}$ of the molasses was adjusted to 6.5 with $4.0 \mathrm{M}$ of $\mathrm{KOH}$.

\section{Medium and growth conditions}

The inoculum was prepared through the transference of $2 \mathrm{~mL}$ of stock culture to Erlenmeyer flasks containing $100 \mathrm{~mL}$ of growth medium (MRS). The MRS growth medium was made up of peptone $(10 \mathrm{~g} / \mathrm{L})$, yeast extract $(5 \mathrm{~g} / \mathrm{L})$, meat extract $(10 \mathrm{~g} / \mathrm{L})$, glucose $(20$ $\mathrm{g} / \mathrm{L})$, sodium acetate $(5 \mathrm{~g} / \mathrm{L})$, ammonium citrate $(2 \mathrm{~g} / \mathrm{L}), \mathrm{K}_{2} \mathrm{HPO}_{4}(5$ $\mathrm{g} / \mathrm{L}), \mathrm{Na}_{2} \mathrm{HPO}_{4} .2 \mathrm{H}_{2} \mathrm{O}(2 \mathrm{~g} / \mathrm{L}), \mathrm{MgSO}_{4} .7 \mathrm{H}_{2} \mathrm{O}(0.1 \mathrm{~g} / \mathrm{L})$ and $\mathrm{MnSO}_{4}$. $4 \mathrm{H}_{2} \mathrm{O}(0.05 \mathrm{~g} / \mathrm{L})$. The inoculated medium was incubated at $37 \pm 1^{\circ} \mathrm{C}$ for $18 \mathrm{~h}$ in a refrigerated incubator (New Brunswick, USA) at 200 rpm. Initial $\mathrm{pH}$ of the medium was adjusted to 6.7 . A total of $10 \%$ $(\mathrm{v} / \mathrm{v})$ of the inoculum was transferred to $250 \mathrm{~mL}$ Erlenmeyer flasks containing $100 \mathrm{~mL}$ of production medium (modified MRS medium) agitated at $200 \mathrm{rpm}$ in a refrigerated incubator at $37 \pm 1^{\circ} \mathrm{C}$ for $48 \mathrm{~h}$.
Calcium carbonate $(100 \mathrm{~g} / \mathrm{L})$ was added to the medium in order to maintain the $\mathrm{pH}$ constant. The modified MRS medium consisted of the same salts as in the growth medium, with the addition of $70 \mathrm{~g} / \mathrm{L}$ of molasses, corn steep liquor ranging from 0 to $30.1 \mathrm{~g} / \mathrm{L}$ and yeast autolysate ranging from 1.475 to $8.525 \mathrm{~g} / \mathrm{L}$. A rotational alpha parameter was used $( \pm 1.41)$.

\section{Central composite design (CCD)}

In order to study the influence of the corn steep liquor (CSL) and yeast autosylate (YA) in the synthesis of lactic acid by the Lactobacillus $\mathrm{sp}$. LMI8 isolate, a central composite design (CCD) was used, with 3 replicates at the center, totaling 11 experiments. The experimental design was determined using the statistica 7 software program. The variables of the experiments were coded according to the following equation:

$$
x_{i}=\frac{\left(X_{i}-X_{c p}\right)}{\Delta X_{i}}
$$

where $x i$ is the coded value of an independent variable, $X i$ is the real value of an independent variable, $X_{c p}$ is the real value of an independent variable at the center point, and $\Delta X i$ is the step change value.

\section{Analytical methods}

Substrate consumption and lactic acid concentrations (sample of 20 $\mu \mathrm{L}$ ) were determined using a high performance liquid chromatography system (Waters Co., Milford, MA) equipped with a tunable UV detector set at $210 \mathrm{~nm}$. An Aminex HPX-87H ion-exchange column $(300 \times 7.8 \mathrm{~mm}$, Bio-Rad, Hercules, CA) was eluted with $0.005 \mathrm{~N}$ of $\mathrm{H} 2 \mathrm{SO} 4$ as a mobile phase at a flow rate of $0.6 \mathrm{ml} / \mathrm{min}$. Column temperature was maintained at $60^{\circ} \mathrm{C}$ and a refraction index (RI) detector was used.

$\mathrm{D}(-)$ Lactic acid concentrations were determined by an enzyme test kit (R-biopharm AG - Roche, Darmstadt, Germany), as reported elsewhere (Yun et al., 2003). Cell growth was measured by a UV160 A spectrophotometer (Shimadzu Co., Tokyo, Japan) set at 650 $\mathrm{nm}$. Dry cell weight was determined by a calibration curve associated to optical density at $650 \mathrm{~nm}$ for dry weight $(\mathrm{g} / \mathrm{L})$.

\section{RESULTS AND DISCUSSION}

\section{Optimization of fermentative production of lactic acid}

The influence of corn steep liquor and yeast autolysate on the fermentation of sugarcane molasses was studied using CCD with three replicates at the center, totaling 11 experiments. The results are displayed in Table 1.

Analyzing Table 1, the best results of all the responses evaluated were obtained in the experiments located at the central point (Experiments 9, 10 and 11). Comparing Experiment 5 with Experiments 9, 10 and 11, performed with the lowest and highest concentrations of CSL ( 0 and $15 \mathrm{~g} / \mathrm{L})$ and equal concentrations of $Y A(5 \mathrm{~g} / \mathrm{L})$, it is evident that lactic acid production was directly proportional to the increase in CSL, reaching a maximal value of $41.42 \mathrm{~g} / \mathrm{L}$ in $32 \mathrm{~h}$ of fermentation. Moreover, the increase in the nitrogen concentration in the fermentative medium 
Table 1. Results of lactic acid production obtained in experiments employing the LMI8 isolate.

\begin{tabular}{|c|c|c|c|}
\hline Experiments & CSL (g/L) & YA (g/L) & Lactic acid (g/L) \\
\hline 1 & 4.3 & 2.5 & 15.32 \\
2 & 4.3 & 7.5 & 20.43 \\
3 & 25.7 & 2.5 & 35.23 \\
4 & 25.7 & 7.5 & 22.7 \\
5 & 0 & 5 & 12.11 \\
6 & 30.1 & 5 & 25.39 \\
7 & 15 & 1.47 & 24.16 \\
8 & 15 & 8.52 & 31.27 \\
9 & 15 & 5 & 41.42 \\
10 & 15 & 5 & 41.23 \\
11 & 15 & 5 & 39.98 \\
\hline
\end{tabular}

Concentration of corn steep liquor (CSL); Concentration of yeast autolysate (YA).

led to a reduction in fermentation time, reaching maximal lactic acid production. Wee et al. (2006) studied the effect of CSL on lactic acid production using different concentrations (15 to $60 \mathrm{~g} / \mathrm{L}$ ) and obtained the same final concentration of lactic acid in all experiments, but the time needed to achieve this concentration decreased signifi- cantly when using greater concentrations of CSL. Yu et al. (2007) used sugarcane molasses ranging from 12 to $60 \mathrm{~g} / \mathrm{L}$ and $\mathrm{CSL}$ ranging from 24 to $56 \mathrm{~g} / \mathrm{L}$ and report that the increase in molasses and CSL provided greater lactic acid production in a shorter fermentation time. Altaf et al. (2006) report that peptone and yeast extract are the main nitrogen sources used for the production of lactic acid and if alternative sources were used, the final product would be smaller and the fermentation time would in-crease. This likely occurs because yeast extract is an excellent source of $B$ complex vitamins and is often used to provide these factors to the bacteriological culture me-dia, which are often considered indispensable to obtain-ing faster growth and production rates of lactic acid by lactic bacteria (Selmer-Olsen and Sorhaug, 1998). The high cost of yeast extract, however, has a negative im-pact when used in industrial processes (Hurok et al., 2005).

In Experiment 5 (Table 1), there was lactic acid production in the absence of CSL. Despite being less significant within the fermentation process (Equation 1), YA provided a good interaction with CSL, generating greater lactic acid production. It should be stressed that calcium carbonate plays a crucial role in lactic acid fermentation, as it buffers the medium. During the production of lactic acid, calcium car-bonate is converted into calcium lactate and maintains the $\mathrm{pH}$. The presence of $10 \%(\mathrm{w} / \mathrm{v})$ calcium carbonate in the production medium was found to be good for lactic ing of the $\mathrm{pH}$, which adversely affected bacterial growth.

The precision of the results of the experiments can be

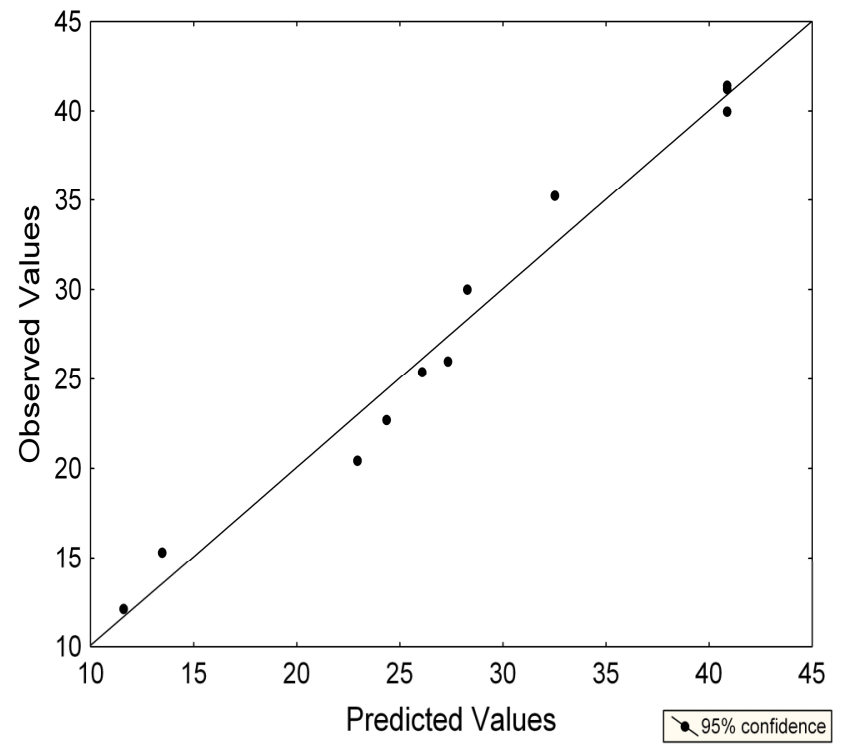

Figure 1. Predicted vs. experimental values plot for lactic acid.

seen in the assessment of the results obtained at the central point of the design, where the difference between responses was close to $1 \%$.

The identification of significant parameters was performed through testing the hypotheses using the student's ttest. The maximal likelihood of error on the test was estaacid production in both cases. In the control, the accumulation of lactic acid was inhibited because of the lowerblished as $5 \%$. Thus, parameters with a level of significance greater than $5 \%$ were discounted.

The adjusted empirical equation that represents the synthesis of lactic acid is expressed in Equation 2:

Lactic acid $=40.876+5.12 \mathrm{X}_{1}-4.41 \mathrm{X}_{1} \mathrm{X}_{2}-11.01 \mathrm{X}_{12}-$ $6.53 \mathrm{X}_{22}$

The goodness of fit of the model was checked by the determination coefficient $\left(R^{2}\right)$ and multiple correlation coefficient $(R)$. In this case, the value of the $R^{2}(0.96)$ for Equation 2 indicates that the sample variation of $96.0 \%$ for lactic acid was attributed to the independent variables and only $4 \%$ of the total variation cannot be explained by the model. The value of the adjusted determination coefficient (adjusted $R^{2}=0.935$ ) is also high, which stresses the significance of the model. The high value of $\mathrm{R}(0.98)$ demonstrates a high degree of agreement between the experimental observations and predicted values. This correlation is also proven by the plot of predicted versus experimental values of lactic acid in Figure 1 , as all the points cluster around the diagonal line, which means that no significant violations of the model were found.

The effects of the independent variables and their interactions on the formation of the product are illustrated 

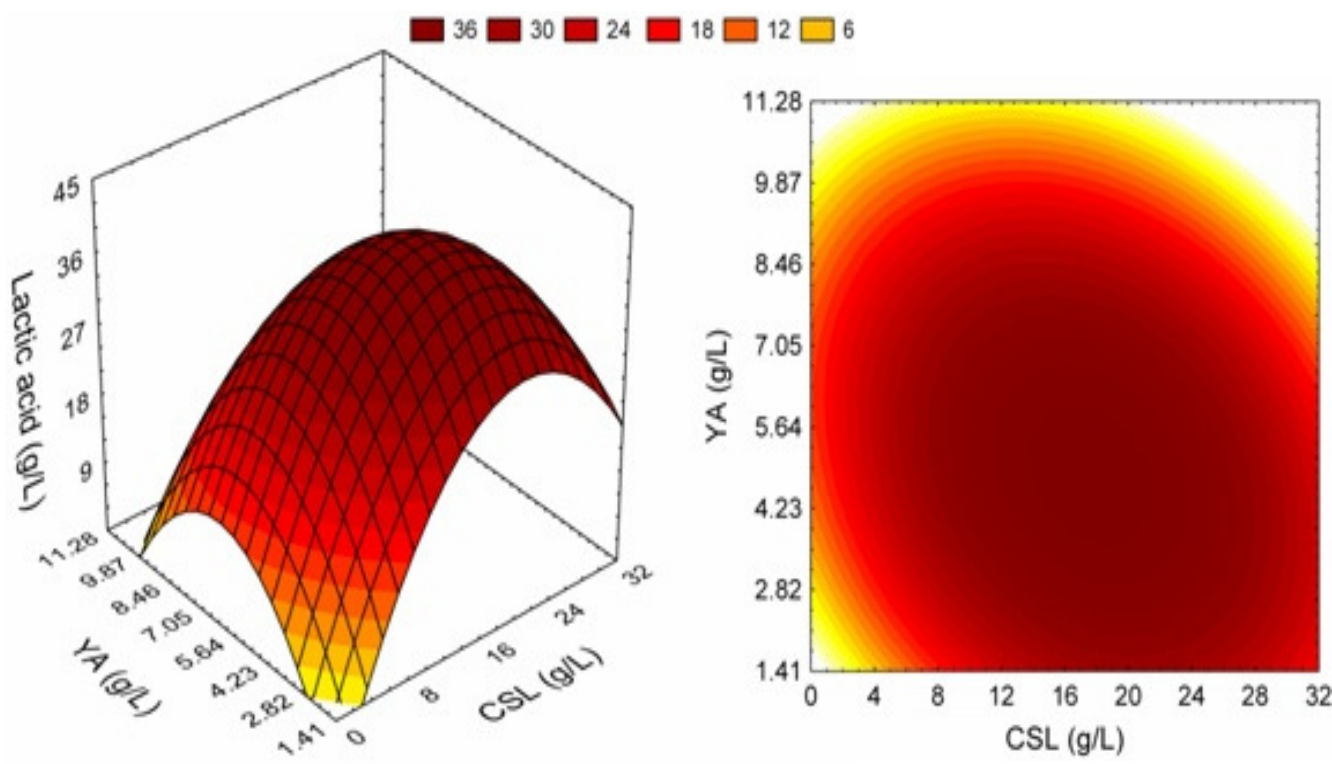

Figure 2. Response surface and contour curve representing the effects of corn steep liquor and yeast autolysate concentrations on lactic acid production.

Table 2. Stationary point for lactic acid production and coded $x_{1}$ and $x_{2}$ values at the optimization point.

\begin{tabular}{|c|c|c|c|}
\hline P0 & Lactic acid & Coordinates & Lactic acid \\
\hline$\lambda_{1}$ & -12.233 & $\mathrm{x}_{1}$ & 0.139 \\
$\lambda_{2}$ & -5.833 & $\mathrm{x}_{2}$ & -0.029 \\
\hline
\end{tabular}

in the analysis of the response surfaces (Figure 2) constructed from Equation 2.

Analyzing Figure 2, maximal lactic acid production occurred when nitrogen concentrations were near $15 \mathrm{~g} / \mathrm{L}$ (CSL) and $5 \mathrm{~g} / \mathrm{L}(\mathrm{YA})$. For greater and lower concentrations of CSL and YA, there was a reduction in response, likely due to either a lack or excess of nitrogen in the fermented medium. According to Wood and Holzapfel (1995) the genus Lactobacillus has complex nutritional requirements. As lactic acid synthesis through fermentation is associated to cell growth, there is no formation of product if the medium does not have an adequate concentration of nitrogen in order to promote this growth (Pritchard and Coolbear, 1993). On the other hand, high concentrations of nitrogen may lead to cell death and inhibition of the product.

An algorithm carried out on the Maple 9.5 program (Waterloo Maple, Inc., Canada) was used to calculate the stationary point $\left(\mathrm{P}_{0}\right)$ for synthesis of lactic acid. These values are displayed in Table 2 . The $\lambda$ values indicate that these responses have a maximal point, as they have equal and negative signs. Lactic acid production was $41.52 \mathrm{~g} / \mathrm{L}$ at the optimization point from the coded $\mathrm{x} 1$ and $x 2$ values (Table 2 ).

Comparing this value with lactic acid production values in experiments 9, 10 and 11 (Table 1), the results were practically the same, as the conditions of the maximal point were near to those of the central point. Thus, the corresponding values for the optimal concentrations of CSL and YA were 16.48 and $4.93 \mathrm{~g} / \mathrm{L}$, respectively. The model predicted a maximal response of $41.38 \mathrm{~g} / \mathrm{L}$ of lactic acid at this point.

Wee et al. (2006) produced $48.6 \mathrm{~g} / \mathrm{L}$ of lactic acid using wood hydrolysate (equivalent to $50 \mathrm{~g} / \mathrm{L}$ of glucose) supplemented with $60 \mathrm{~g} / \mathrm{L}$ of CSL in $36 \mathrm{~h}$ of fermentation.

Bustos et al. (2004) obtained maximal lactic acid production $(58.9 \mathrm{~g} / \mathrm{L})$ in $96 \mathrm{~h}$ of culturing using $5 \mathrm{~g} / \mathrm{L}$ of $\mathrm{CSL}$ together with $3.6 \mathrm{~g} / \mathrm{L}$ of yeast extract and $10 \mathrm{~g} / \mathrm{L}$ of peptone. Using a mathematical model furnished the response surface method, Hauly et al. (2003) determined maximal concentrations values tested for sugarcane molasses (100 g/L), yeast extract $(20 \mathrm{~g} / \mathrm{L})$ and peptone (4 $\mathrm{g} / \mathrm{L}$ ) as the best medium composition for the production of lactic acid. In practice, these conditions provided a production of $30.5 \mathrm{~g} / \mathrm{L}$ of lactic acid.

\section{Conclusion}

The central composite design proved to be a very useful and applicable tool for determining the behavior of the variables studied in the production of lactic acid, thereby avoiding excessive analyses and offering generalized information on the influence of the independent parameters in the process. The Lactobacillus sp. LMI8 strain used in the present study achieved significant results regarding lactic acid production using corn steep liquor and yeast autolysate. Under optimal conditions (16.48 g/L of CSL and $4.93 \mathrm{~g} / \mathrm{L}$ of $\mathrm{YA}$ ) a lactic acid concentration of $41.52 \mathrm{~g} / \mathrm{L}$ was obtained. 


\section{ACKNOWLEDGEMENT}

We thank the Fundação de Amparo à Pesquisa de Estado de São Paulo (FAPESP) for fellowships and financial support.

\section{REFERENCES}

Altaf Md, Naveena BJ, Venkateshwar M, Vijay Kumar E, Reddy G (2206). Single step fermentation of starch to $L(+)$ lactic acid by Lactobacillus amylophilus GV6 in SSF using inexpensive nitrogen sources to replace peptone and yeast extract-Optimization by RSM. Process Biochem. 41: 465-472.

Beaulieu M, Beaulieu Y, Mélinard J, Pandian S, Goulet J (1995). Influence of ammonium salts and cane molasses on growth of alcaligenes eutrophux and production of polyhydroxybutyrate. Appl. Environ. Microbiol. 61: 165-169.

Bustos G, Moldes AB, Alonso JL, Vázquez M (2004). Optimization of Dlactic acid production by Lactobacillus coryniformis using response surface methodology. Food Microbiol. 21: 143-148.

Datta R, Henry M (2006). Lactic acid: recent advances in products, processes and technologies- A review. J. Chem. Technol. Biotechnol. 81: 1119-1129.

Datta R, Tsai SP, Bonsignore P, Moon SH, Frank JR (1995). Technological and economic potential of poly-lactic acid and lactic acid derivatives. FEMS Microbiol. Rev. 16: 221-231.

Chotani G, Dodge, T, Hsu A, Kumar M, LaDuca R, Trimbur D, Weyler W, Sanford K (2000). The commercial production of chemicals using pathway engineering. Biochem. Biophy. Acta. 543: 434-455.

El-Sherbiny GA, Rizk SS, Yousef GS (1986). Utilization of beet molasses in the production of lactic acid. Egypt J. Food Sci. 14: 91100.

Focus L (1975). Focus Uppslagsböcker AB, Stockholm, Sweden.

Gomes AMP, Malcata FX (1999). Bifidobacterium spp. and Lactobacillus acidophilus: Biological, biochemical, technological and therapeutical properties relevant for use as probiotics. Trends Food Sci. Technol. 10: 139-157.

Hauly MCO, Oliveira AR, Oliveira AS (2003). Lactic acid production by Lactobacillus curvatus in sugarcane molasses-Semina: Ciências Agrárias, Londrina, 24: 133-142.

Hofvendahl K, Hahn-Hagerdal B (2000). Factors affecting the fermentative lactic acid production from renewable sources. Enzyme. Microb. Technol. 26: 87-107.

Hurok Oh, Wee WJ, Yun JS, Han SH, Jung S, Ryu HW (2005). Lactic acid production from agricultural resources as cheap raw materials. Bioresour. Technol. 96: 1492-1498.
Ikada Y, Jamshidi K, Tsuji H (1987). Stereocomplex formation between enantiomeric poly (lactides). Macromolecules, 20: 904-906.

Moraes IO, Capalbo DMF, Moraes RO (1991). Multiplicação de agentes de controle biológico. In: Bettiol W, Controle Biológico de Doenças de Plantas. Brasília: EMBRAPA, pp. 253-272.

Pritchard GG, Coolbear T (1993). The physiology and biochemistry of the proteolitic system in lactic acid bacteria. UFEMS Microbiol. 12: 179-206.

Roy MK, Kuwabara Y, Hara K, Watanabe Y, Tornai Y (2002). Peptides from the $\mathrm{N}$-terminal end of bovine lactoferrin induce apoptosis in human leukemic (HL-60) cells. J. Dairy Sci. 85: 2065-2074.

Schepers AW, Thibault J, Lacroix C (2002). Lactobacillus helveticus growth and lactic acid production during $\mathrm{pH}$-controlled batch cultures in whey permeate/yeast extract medium. Part I. Multiple factor kinetic analysis. Enzyme Microb. Technol. 30: 176-186.

Selmer-Olsen E, Sorhaug T (1998). Comparative studies of the growth in whey supplemented with autolysate from brewery yeast biomass or commercial yeast of Lactobacillus plantarum extract. Milchwissenschaft, 53: 367-370.

Takaaki T, Hoshina M, Tanabe S, Sakai K, Ohtsubo S, Taniguchi M (2006). Production of D-lactic acid from defatted rice bran by simultaneous saccharification and fermentation. Bioresour. Technol. 92: 211-217.

Tiwari KP, Pandey A, Mishra N (1979). Lactic acid production from molasses by mixed population of Lactobacilli. Zentl Bakteriol. 134: 544-546.

Tsuji H, Hyon SH, Ikada Y (1991). Stereocomplex formation between enantiomeric poly (lactides). Calorimetric studies on blend films cast from dilute solution. Macromolecules, 24: 5651-5656.

Wee YJ, Yun JS, Kim D, Ryu HW (2006). Batch and repeated batch production of $\mathrm{L}(+)$-lactic acid by Enterococcus faecalis RKY1 using wood hydrolyzate and corn steep liquor. J. Indus. Microbiol. Biotechnol. 33: 431-435.

Wood BJB, Holzapfel WH (1995). The Genera of Lactic Acid Bacteria. Glasgow: Blackie Academic \& Professional, USA.

Yu MC, Wang RC, Wang CY, Duan KJ, Sheu DC (2007). Enhanced production of $\mathrm{L}(+)$-lactic acid by floc-form culture of Rhizopus oryzae. J. Chinese Inst. Chem. Eng. 38: 223-228. 